\title{
MIGRACIÓN DE JÓVENES GUATEMALTECOS: NOCIONES DE MASCULINIDAD Y EL PODER DE LA IMAGINACIÓN
}

Sarah Dietrich ${ }^{1}$

\author{
Recibido: 14/02/2016 Aceptado: 26/04/2016
}

\begin{abstract}
Resumen
Este artículo busca desentrañar la relación entre nociones de masculinidad y significados socioculturales de la migración de jóvenes guatemaltecos, quienes fueron detenidos en su camino ilegalizado a Estados Unidos y deportados a Guatemala desde México. Se plantea como hipótesis que la migración de jóvenes cobra relevancia en cuanto a procesos de socialización y subjetivación en el marco de la adolescencia como espacio de "(no)posibilidad". Al mismo tiempo, se explora la importancia que adquieren los imaginarios sociales del "Norte" y la imaginación de estos jóvenes actores. Para ello, se hace una relectura de datos empíricos recabados durante un periodo de 3 meses de trabajo de campo etnográfico en un centro estatal guatemalteco de asistencia a menores no acompañados deportados desde México y Estados Unidos en el 2009.
\end{abstract}

Palabras clave: migración; jóvenes; menores no acompañados; motivos; imaginación.

\begin{abstract}
This article seeks to unravel the relationship between notions of masculinity and socio-cultural meanings of migration for young Guatemalans, who were detained on their illegalized way towards the USA and deported to Guatemala from Mexico. It is hypothesized that youth migration becomes meaningful in regard to processes of socialization and subjectivation in the scope of adolescence as a space of "(im) possibilities". At the same time, the importance of social imaginaries of the 'North' and the significance of these young actors' imaginations is explored. For this purpose, empirical data from 2009 is reexamined. The material had been gathered during three months of ethnographic fieldwork in a Guatemalan state-run center assisting unaccompanied minors deported from Mexico and the United States.
\end{abstract}

Keywords: migration; youth; unaccompanied migrant minors; motives; imagination. 


\section{Introducción}

Míralos marchándose en masa, los hijos del país, solamente míralos marchándose en masa. Aquellos que no tienen nada están cruzando las fronteras. Aquellos que tienen fuerza están cruzando las fronteras. Aquellos que tienen ambiciones están cruzando las fronteras. Aquellos con esperanza están cruzando las fronteras. Aquellos que han tenido pérdidas están cruzando las fronteras. Aquellos con sufrimiento están cruzando las fronteras... Se marchan en masa.

(Bulawayo, 2014: 145). ${ }^{2}$

... Quédate aquí en tu tierra / Quédate en tu país / El tiempo está cambiando trabajamos para ti / Quédate en Guatemala, vamos a reconstruir este país hermoso que tiene gran porvenir, aquí en Guatemala / Eres el motor que impulsa esta gran nación, con tu esfuerzo y tu trabajo haremos un país mejor / Guatemala necesita gente buena y dispuesta trabajando con el alma y el corazón (Campaña "Quédate" de la Secretaría de Bienestar Social de la Presidencia de la República de Guatemala, 2014).

La denominada "crisis de lxs ${ }^{3}$ refugiados" en Europa evoca imágenes de otra "urgente crisis humanitaria" que con los avatares de la economía de atención mediática parece haber caído un tanto en el olvido. Esta involucra a nuevos actores migratorios y fue declarada por el gobierno de Obama en el año 2014, ante la llegada de 52000 "menores centroamericanos no acompañados" a la frontera sur de EE. UU., entre octubre de 2013 y junio de 2014 (Tuckmann, 9 de julio de 2014). ${ }^{4}$

Casi 10 años antes de estos acontecimientos, la oficina del Procurador de los Derechos Humanos (PDH) de Guatemala ya había descrito el aumento acelerado de la cifra de niñas ${ }^{*}$ niños ${ }^{* 5}$ y jóvenes ${ }^{6}$ guatemaltecos, movilizándose independientemente del acompañamiento de un familiar hacia "el Norte", como un "éxodo" (PDH, 2005: 7). Mientras cada vez más jóvenes han salido de Guatemala, El Salvador y Honduras con destino "al Norte", se ha incrementado el número de detenciones y deportaciones de estos actores a través de los últimos años (véase Observatorio de Legislación y Política Migratoria, 28 de enero de 2016). En la actualidad hay una extensa cantidad de publicaciones de diferentes índoles que tematizan las causas y los motivos por los cuales lxs jóvenes guatemaltecos/centroamericanos se marchan "al Norte" (RELAF y Save the Children y UNICEF, 2014; Girón Solórzano, 2014; Musalo y Ceriani Cernadas, 2015; PDH, 2005; Escobar Sarti, 2008 para mencionar solamente algunos). Con la declaración de la "crisis humanitaria" por la administración estadounidense en el 2014 ha habido un aumento significante de publicaciones en los medios de comunicación, con el propósito de explicar la motivación de estos jóvenes actores. Sin embargo, el discurso mediático estriba, en su mayoría, en paradigmas descartados por la academia. 
Además, prevalece la tendencia de reducir la línea explicativa en relación con la movilidad de jóvenes a proyecciones casi mecánicas y unidimensionales de factores tales como push y pull, lo cual limita la comprensión de estas prácticas migratorias.

Dicho lo anterior, este aporte pretende desentrañar la relación entre las nociones de masculinidad y los significados socioculturales de la migración de jóvenes guatemaltecos, quienes fueron detenidos en su camino ilegalizado a EE. UU. y deportados a Guatemala desde México. Al mismo tiempo, el artículo trata de dilucidar el papel que desempeñan los imaginarios sociales del "Norte" y la imaginación de los jóvenes actores.

A partir del material empírico, se desarrolló la hipótesis que la migración de jóvenes adquiere sentido más allá de las razones que se le asocian. Al respecto, las entrevistas evidenciaron que la migración con fines concebidos primordialmente como laborales, es decir, prácticas migratorias iniciadas con la intención de trabajar en México y los EE. UU., también cobra relevancia en cuanto a procesos de socialización y subjetivación en el marco de la adolescencia como espacio de "(no)posibilidad" (Mecheril y Hoffarth, 2009). Como lo precisa Henrik Vigh en el context de la migración de jóvenes de Guinea Bissau: "la simplicista hipótesis subyacente, que el dinero es el meollo del asunto para los jóvenes migrantes, resulta inadecuada ya que reduce las complejas motivaciones sociales a una simple lógica económica" (2009: 92. Traducción propia, S.D.). ${ }^{7}$

\section{La investigación}

El presente aporte sigue la línea de investigación recopilada dentro del trabajo de campo para la elaboración de una tesis de maestría en Antropología Social y Cultural (Dietrich, 2010). ${ }^{8}$ Considerando lo propuesto por O'Connell Davidson y Farrow (2007), quienes señalaban la necesidad de enfocar y conocer el autoposicionamiento de los actores mismos, la investigación llevada a cabo en el 2009 buscó acercarse a un entendimiento de las interpretaciones y posicionamientos de jóvenes guatemaltecos que habían sido deportados desde México, frente a los procesos de (in)movilidad que protagonizaban. Aunque durante la última década la migración de jóvenes ha cobrado más visibilidad en toda América (véase Girón Solórzano, 2014; Escobar Sarti, 2008; Uehling, 2008; Falla, 2006 y 2008; RELAF y Save the Children y UNICEF, 2015), los escasos datos disponibles en el 2009 eran en su mayoría de índole cuantitativa.

A diferencia, la observación participante que se llevó a cabo durante 12 semanas era de carácter cualitativo. Se realizaron 28 entrevistas semiestructuradas con jóvenes de entre 14 y 18 años de género masculino*, quienes representaban (y aún representan, véase Girón Solórzano, 2014) el grupo más grande de personas atendidas en el centro. El análisis de las entrevistas se basó en el desarrollo de códigos teóricos de manera inductiva, lo cual permitió que los códigos emergieran del material empírico. 
Como método complementario se les propuso a las y los jóvenes actores migratorios elaborar dibujos de sus experiencias durante el viaje al "Norte" y de cómo lo imaginaban, entre otros. Además se realizó una observación participante en el centro de detención más grande de México, acompañando un grupo de jóvenes guatemaltecxs en el trayecto de deportación vía terrestre de México hacia Guatemala.

El Global Detention Project (2013) califica esta "Estación Migratoria Siglo XXI" en Tapachula como una "institución cerrada". En un reciente comunicado de prensa, el Centro de Derechos Humanos Fray Matías de Córdoba A. C. denuncia la violación de los derechos de las personas que son detenidas en este centro bajo el título: "Privación indefinida de libertad y violaciones de derechos, persisten en el centro de detención para migrantes de Tapachula, ante la mirada y colaboración de funcionarios estadounidenses" (2016). Cabe destacar que muchos de los jóvenes entrevistados usaban los términos "cárcel" o "prisión" para referirse a los centros donde estuvieron albergados en Estados Unidos, México y también en Guatemala. En una publicación del año 2015 me enfoqué en este tema, sugiriendo cuestionar la práctica de detención, institucionalización y deportación de estos actores (véase también RELAF y Save the Children y UNICEF, 2015; Musalo y Ceriani Cernadas, 2015). Señalé que prácticas estatales ambiguas, tales como la protección a través de la detención y el encierro, en las cuales se manifiestan repercusiones de nociones normativas de infancia y juventud, son interpretadas por algunos de los jóvenes entrevistados como sanción y criminalización de su agencia. Igualmente, y en consonancia con otrxs autorxs, identifiqué la necesidad de conducir más investigación cualitativa centrada en las interpretaciones de lxs jóvenes. De esta manera se pudiera dar un aporte a la formulación de políticas públicas estatales menos adultocéntricas y paternalistas, es decir, políticas que conciban a las y los jóvenes como actores migratorios independientes válidos. Con ello ahondé en la discusión que desarrollé en la tesis acerca de debates relacionados con la construcción de la vulnerabilidad de jóvenes migrantes por parte de diferentes actores estatales y no estatales y la relación de la agencia y capacidad de actuar de los "menores" (véase Boyden y Ennew, 1997). Estos debates aún siguen siendo vigentes (Dietrich, 2015; véase también Ensor y Goździak, 2010; Orgocka y Clark-Kazak, 2012). Parece preciso señalar en este contexto que la a priori victimización de "menores no acompañados" es inadecuada, ya que homogeniza las experiencias de los actores.

\section{Los jóvenes entrevistados: un grupo heterogéneo}

Los jóvenes entrevistados constituyeron un grupo heterogéneo en relación con su posición dentro de la lógica de los órdenes hegemónicos de la sociedad guatemalteca, la cual se caracteriza por estructuras altamente desiguales y discriminatorias. Es decir, se diferenciaron en cuanto a su capital social (Bourdieu, 1986), su pertenencia de clase social, recursos financieros, su situación familiar y su pertenencia racializada/etnizada. 
Algunos jóvenes hablaban uno de los idiomas indígenas ${ }^{9}$ aparte del castellano. También distaron en cuanto a su procedencia geográfica: mientras cuatro jóvenes eran de la Región Metropolitana del país, los otros entrevistados provenían del Área Rural. ${ }^{10}$

Además, el objetivo de 25 de los 28 jóvenes entrevistados era llegar a los Estados Unidos de América o a Canadá. Cinco ya se habían establecido en México previo a su detención y deportación o buscaban quedarse en ese país. Todos los entrevistados habían asistido a una escuela, sin embargo, la mayoría abandonó los estudios después de terminar la primaria. Así mismo, para la mayoría de los jóvenes había sido el primer intento de viajar al "Norte", aunque algunos de los entrevistados ya se habían marchado en ocasiones anteriores. Tal es el caso de Jacobo, ${ }^{11}$ un joven de Santa Rosa, quien había intentado llegar a EE. UU. por sexta vez. Más de la mitad de los entrevistados se desplazaron sin utilizar los servicios de un "coyote". Por su parte, muchos de ellos contaban con experiencia laboral en Guatemala previo a la decisión de marcharse (por ejemplo en el ámbito de la agricultura, en el sector informal, en maquilas, en la construcción). Válgase mencionar que solamente cuatro jóvenes no tenían familiar o una persona conocida en México o en los Estados Unidos. A parte de caminar largas distancias, lxs jóvenes usaron varias formas de movilizarse durante el trayecto: como por ejemplo en automóvil, escondidos en tráileres, en autobuses, montados sobre trenes de carga que atraviesan México o en avión. Algunos de los 28 jóvenes fueron secuestrados y sufrieron violencia en manos de los Zetas ${ }^{12}$ mientras que otros fueron víctimas de los abusos contra sus derechos cometidos por las autoridades estatales estadounidenses y mexicanas, tanto en las instituciones donde estuvieron reclutados como durante el camino.

\section{Investigación con jóvenes deportados, dilemas éticos y el rol de la academia}

Antes de desarrollar la argumentación de este artículo, se debe remarcar que en las entrevistas formales no participaron jóvenes mujeres*, aunque durante el trabajo de campo sí llegaron al centro, pero en menor cifra, y sí participaron en la elaboración de los dibujos mencionados como método complementario anteriormente. Esto claramente representa una de las limitaciones de la investigación, pues invisibiliza las posiciones de dichas actoras (véase Dietrich, 2015: 11).

Además, se debe admitir las limitaciones impuestas por los procesos jurídicosadministrativos de la "repatriación" a la práctica investigativa. Por ejemplo, todas las entrevistas se llevaron a cabo en el patio del hogar temporal debido a que lxs jóvenes no estaban autorizados para salir de la institución, ya que aún se encontraban sometidos a dichos procesos (véase Dietrich, 2015). ${ }^{13}$ Como lo advierte Peutz, al realizar investigaciones con personas detenidas, se debe estar consciente del dilema ético que deviene con "esta imitación y continuación etnográfica de la vigilancia de individuos que ya han sido interrogados" (2006: 219). ${ }^{14}$ Esto cobra relevancia en el caso 
de los jóvenes entrevistados que pasaron días, semanas y hasta meses encerrados en el marco de la deportación.

Así, aunque el permiso de investigación en el centro estatal me haya permitido acceder a un espacio restringido, en retrospectiva parece oportuno plantear la interrogante si como investigadora me convertí en "cómplice" de un régimen migratorio, el cual no cuestiona la construcción contradictoria de la "ilegalidad" y, por ende, "deportabilidad" de seres humanos (De Genova, 2002; Chávez, 2007; Coutin, 2005). Por lo tanto, resulta necesario analizar, si la generación de conocimiento académico en este ámbito no puede ser utilizada para el control y la biopolítica estatal (véase Uehling, 2008). En esto se enmarca la necesidad de desentrañar el rol de la academia tal como lo plantea Carlos Sandoval García (2013). ${ }^{15}$

Con respecto a lo señalado, es preciso cuestionar los términos empleados para categorizar a las personas cuyas experiencias se procura estudiar. Siguiendo a De Genova (2002) y Peutz (2006), parece importante no reificar categorizaciones homogeneizantes, sino más bien, desnaturalizarlas. Poniendo en práctica lo dicho, se traslada a la interrogación de la práctica de clasificar a 1xs "menores no acompañados" como tales, ya que ésta se encuentra tajantemente inscrita en la lógica clasificatoria del régimen migratorio estadounidense. Autores como Bhabha (2008) y Orgocka (2012) han indicado que el término legal "menores no acompañados" evoca nociones de una vulnerabilidad particular que a la vez facilita y legitimiza la intervención estatal, recurriendo a la "victimicidad" anticipada de 'children out of place'. De esta manera se prioriza la asistencia estatal sobre las perspectivas de lxs actores mismos (véase Dietrich, 2015: 3). Orgocka, a cambio, sugiere el uso de la expresión "migración infantil independiente" como alternativa "para capturar de manera más adecuada la interconexión de la agencia, el poder y la estructura en el marco de la migración" (Clark-Kazak, 2012: 95. Traducción propia, S.D.). ${ }^{16}$

A luz de lo anterior cabe mencionar la influencia del régimen migratoriofronterizo de los EE. UU. en la criminalización e ilegalización de los actores migrantes no documentados, independientemente de su edad y estado social. Con esto está intrínsecamente vinculado tanto el fenómeno de securitización de las políticas migratorias (véase Sandoval García, 2015) como el negocio lucrativo del complejo militar-industrial estadounidense (Sandoval Palacios, 2014). Este último se expande tanto en territorio estadounidense, como en México y los países centroamericanos, pero de manera externalizada.

\section{Motivos entrelazados: más allá de las líneas explicativas simplicistas}

Roberto, un joven de 15 años del departamento de Guatemala, había intentado llegar a Virginia, Estados Unidos. Él vivía junto a sus padres y cinco de siete hermanos. Durante la entrevista relató que: 
Antes de salir hacia "el Norte" mi vida era normal, pues, o sea, la vida que he tenido de estar con mi familia, lo más bueno que he tenido de estar ahí con ellos y ellos me dan todo lo que quiero y me dan mi comida y todo... Allá [en Estados Unidos, S.D.] están mis hermanos, y todo por las ganas de verlos, porque como uno no los tiene, va, y desde tres años que no los miro y la necesidad de verlos y ahí también siempre, como siempre tengo en, en mi mentalidad de no, siempre no, que mi papá no me esté manteniendo, no, a mí no me gusta así, yo quiero hacer mi dinero yo mismo. Por eso es que decidi yo y por la necesidad que tiene uno también verdad, sí,...es duro [sic] la vida de esto, va, asi que uno tiene que echarle ganas y seguir adelante y todo, si... (Roberto, entrevista, mayo de 2009. Énfasis agregado, S.D.).

En este primer extracto del inicio de la entrevista, Roberto presenta como motivo el haber intentado llegar a EE. UU. para reunificarse con sus hermanos que están viviendo allá, y además habla de la "necesidad de verlos". Al mismo tiempo introduce otro motivo: el deseo de independizarse económicamente de su padre: "yo quiero hacer mi dinero yo mismo"; un anhelo que después califica como una "necesidad". Aquí ya se perfila que la decisión de irse se basa en varios motivos que a su vez parecen estar entrelazados.

\section{S.D.: ¿Y cómo, cómo se te ocurrió irte?}

Roberto: Ah... es que mi papá me dijo, me dijo, él me dijo una vez que si yo quería ir a los Estados Unidos y yo no le había dicho pero sí tengo ganas le dije... y que si mi papá me dijo, mira si querés te consigo un coyote y si querés te vas me dijo, a vaya le dije yo, va, entonces el coyote dijo va, que le estaba cobrando el dinero y le cobró 42 mil quetzales, va, entonces mi papá me dijo, si tenés ganas de irte y entonces yo me puse triste por dentro, me iba a mi cuarto y lloraba y todo, uno de joven así, va, es duro no ver a su familia y todo, uno está acostumbrado a verla y todo, va... pero sí es duro [sic] la vida de eso, la necesidad de ganar mi dinero yo mismo... hacer mi casa, mi carro, mi familia y todo pues... porque es difícil (Roberto, entrevista, mayo de 2009; énfasis agregado, S.D.).

En esta segunda parte, el joven cuenta que fue su padre quien lo incentivó a concretar la idea de irse y quien lo apoyó buscándole un "coyote" y pagando sus "servicios". Roberto se conmovió profundamente al darse cuenta que salir al "Norte" significa dejar de ver a su familia. Sin embargo, en este contexto Roberto argumenta que aunque le entristezca, debe irse por "la necesidad de ganar mi dinero yo mismo... hacer mi casa, mi carro, mi familia". Así, lo que se había presentado primero como deseo y después como necesidad, adquiere un carácter aún menos optativo, convirtiéndose en una obligación. En este contexto parece preciso remitir a Ensor y Goździak, quienes sostienen: 
... migrantes jóvenes suelen asumir un rol activo en cuanto a evaluar su propia situación, tomando decisiones que conciernen sus trayectorias de vida y negociando los desafíos y las oportunidades que el desplazamiento les ofrece. A pesar de que puedan experimentar la migración como resultado de sus circunstancias personales, la opción de migrar de por sí es producida socialmente. (2010: 3. Traducción propia, S.D.). ${ }^{17}$

\section{Migración y deportación: normas de género y significados socioculturales}

Para entender las diferentes dinámicas de las prácticas migratorias pareciera ser clave, enfocar el hecho que jóvenes guatemaltecxs crecen en espacios sociales transnacionales, los cuales están profundamente entrelazados con la historia migratoria hacia "el Norte": "Estos espacios sociales no solamente consisten de remesas financieras e imaginarios compartidos, sino también de personas y familias moviéndose de aquí para allá (voluntariamente e involuntariamente) de una manera dinámica pero a la vez entrelazada" (Dietrich, 2015: 2, Traducción propia, S.D.). ${ }^{18}$

Por ende, estas redes transnacionales y su "cultura de recepción" también subyacen en la movilidad de lxs jóvenes. En este sentido, varixs autorxs desarrollan el concepto de la migración como "práctica cultural" o "regla cultural" que normaliza el proyecto migratorio indocumentado (por ejemplo Arriola, 1999, cit. en Camus, 2008; Kron, 2008; Salazar, 2011).

Hondagneu-Sotelo señala que las redes transnacionales, en el caso empírico de la migración de México hacia EE. UU., históricamente han sido "redes exclusivamente masculinas [las cuales] favorecen la migración de los hombres" (1994: 188. Traducción propia, S.D.). ${ }^{19}$ Las relaciones y nociones de género y la práctica migratoria están intrínsecamente entrelazadas, tal como lo han manifestado varios autores ${ }^{20}$ (Pierrette Hondagneu-Sotelo, 1994; Broughten, 2008). ${ }^{21}$ De esta manera, la migración puede ser entendida como "prueba de masculinidad" (Camus, 2008: 299), que a la vez "se convierte en expectativa entre los hombres jóvenes y solteros" (Hondagneu-Sotelo, 1994: 84. Traducción propia, S.D.). Así, la movilidad pronunciada de jóvenes, en su mayoría hombres", también es conceptualizada como "rito de iniciación patriarcal" (Hondagneu-Sotelo, 1994: 83. Traducción propia, S.D.):

Se sabe con certeza que los jóvenes hombres son gradualmente integrados a una cultura de migración hacia el norte en muchas regiones de México. Sostenido por redes sociales transnacionales y la gloria de los migrantes retornados, el folclore popular define el viaje hacia el norte como un rito de iniciación. (Hondagneu-Sotelo, 1994: 191. Traducción propia, S.D.). ${ }^{22}$

Al mismo tiempo, Hondagneu-Sotelo señala que la motivación de las jóvenes mujeres*, al igual que la de los hombres, ha sido emprender el viaje para conocer EE. UU. y "para obtener una determinada cantidad de dinero" (1994: 87. Traducción propia, S.D.). ${ }^{23}$ 
En el contexto guatemalteco Stefanie Kron señala que "la emigración predominantemente masculina implica, además, que el componente de género marca el tipo de participación en el ciclo migratorio" (2008: 401). Por lo tanto, un posible eje de interpretación apunta hacia la práctica migratoria como "repetición ritualizada de convenciones sociales" (Butler, cit. en Romano, 1999: 325) y a la vez como "doing gender" (West y Zimmermann, 1987). En el caso de la migración (no solo de jóvenes) esto está tajantemente vinculado con las relaciones globales de desigualdad subyacentes a un régimen económico de capitalismo neoliberal y, por ende, con una división internacional de trabajo que requiere de "mano de obra barata". Al respecto Hondagneu-Sotelo argumenta, "de esta manera, el trabajo masculino migrante es producido a través del patriarcado a beneficio del capital estadounidense" (1994: 188. Traducción propia, S.D.). ${ }^{24}$ Estas condiciones, a su vez, engendran "masculinidades dominadas" y "marginalizadas", en el contexto de la vida con estatus migratorio de indocumentado en los EE. UU. (Hondagneu-Sotelo y Messner, 1994).

Según la percepción de Ramona Pérez, esta marginalización se profundiza en el caso de la detención y deportación de los jóvenes actores, tal como lo plantea la autora al basarse en su investigación con "menores no acompañados" detenidos en EE. UU. y deportados a México:

En ambos lados de la frontera, los cuerpos de los jóvenes hombres han dejado de evocar imágenes de fuerza, estabilidad y éxito cuando se les imposibilita desempeñar su masculinidad; a cambio, en ambos países, pero por razones diferentes, han llegado a representar el fracaso. La realidad de que muchos de ellos se encontrarán de regreso en la calle, con o sin familia, es real y refuerza un sistema de discriminación de género el cual los marca públicamente como fracasados y asegura su derrota al buscar ser proveedores exitosos para sus familias. Ninguno de los dos países les ofrece a estos jóvenes una oportunidad para verse a sí mismos como hombre adulto exitoso, el que no será marcado por el intento fracasado de migrar. (Pérez, 2012: 79. Traducción propia, S.D.). ${ }^{25}$

La autora procede a denunciar estos acontecimientos como "violencia estructural". Así, Roberto, después de enfatizar en su narración "lo duro" y hasta insoportable de "irse" al "Norte", por más sufrimiento emocional y físico que le haya causado, a la hora de la entrevista, él estaba decidido a emprender nuevamente el itinerario, no más saliera del centro de acopio:

Roberto: ... Le dan más ganas a uno, ya sabe, para mí, en este fue una experiencia muy grande pues, una experiencia, whhh, ya sé yo que, ya no me agarran, tengo la mentalidad que ahora, sabe que, uno a cada garrita tiene que darle vuelta, va, y no en la garrita, no tienes que pasar porque siempre te bajan, va, y los soldados, ellos, ellos tienen que responder claro y ellos no, ellos no reciben dinero porque son soldados, pero si la policía federal y todo migración reciben dinero, para mí va ser más fácil, porque ya sé cómo, ya sé que hay 
que hablarle más fuerte a los de migración y no agachar la cabeza o algo, ya uno, uno, tantas cosas aprende y ahorita ya voy diciendo, que si me agarran, ya voy a decir que soy mayor de edad, no, yo soy mayor de edad, voy a decir que soy del 90 o algo asi, tengo que mentir va, ya para llegar (Roberto, entrevista, mayo de 2009. Énfasis agregado, S.D.).

En consonancia con lo previamente señalado, frente a la intención de Roberto de tratar nuevamente llegar "al Norte", motivo que también manifestaron 16 de los 28 jóvenes entrevistados durante el trabajo de campo (otros 3 lo estaban considerando), una línea de interpretación puede ser la de rehusarse a aceptar el "haber fracasado" en realizar el proyecto migratorio. ${ }^{26}$

Por otro orden, y aparte de enfatizar su proceso de aprendizaje en la narración, Roberto encuentra una manera de darle sentido a su intento fracasado de cruzar la frontera estadounidense (Scheper-Hughes, 2008), enfocando que, esto sí, al próximo intento estaría mejor preparado: decidido a hablarles más fuerte a los agentes migratorios, sin bajar la vista, con la estrategia de decir que era mayor de edad si lo volvieran a detener, para no llegar a estar encerrado nuevamente. ${ }^{27}$

Más adelante, Roberto agrega:

Yo si voy a regresar [a Guatemala, S.D.], yo por eso voy a trabajar, a echarle ganas y todo, o sea en mi pensamiento estaba cuatro años nada más, hacer mi casa, mi dinero, tal vez me pudiera casar, no sé, va, pero ya cuando tuviera mi edad que ya supiera que es lo de tener una familia y todo, va (entrevista, mayo de 2009. Ènfasis agregado, S.D.).

De esta manera, el proyecto migratorio del joven también reproduce y reifica las normas naturalizadas en cuanto a las metas trazadas en el marco de una biografía "normal" para un joven, con lo cual se cumple con las nociones de masculinidad heteronormativas. Al respecto, resalta que Roberto ve la migración a EE. UU. y el trabajo precario allá como única manera de alcanzar estas metas. En la entrevista dice no haber estado trabajado sino estudiando antes de salir de Guatemala, resulta significativo, entonces, que el adquirir diplomas educativos, ya sea graduarse de bachiller o estudiar en la universidad, no forman parte de la estructura de oportunidades que percibe a su alcance, aunque cuenta con el capital social y financiero para hacerlo. Tampoco no parecen formar parte de la visión de su padre, siendo él quien le presentó con la oportunidad de irse, lo cual es sorprendente, ya que, según contó Roberto, su padre se sentaba a revisarle las tareas y lo apoyaba en los estudios. Desde esta perspectiva, el proyecto migratorio adquiere un sentido sociocultural y cobra significancia en cuanto a procesos de constitución de subjetividad y de procesos de socialización vinculados intrínsecamente con nociones de masculinidad. 
En el caso de lxs jóvenes, estos procesos se llevan a cabo en un espacio de acción y negociación de adolescencia construido socialmente, "en el cual valores y prácticas culturales son transmitidos de una generación a la siguiente y en el cual a la vez se constituye algo nuevo" (Busche, 2014: 222. Traducción propia, S.D.). ${ }^{28}$ Lxs jóvenes, por ende, están inmersos en un proceso creativo que a la vez se ve limitado por las condiciones impuestas por la sociedad y el entorno social (Busche, 2014: 224). Entonces se destaca que lxs jóvenes actores, para asumir la autoría de una posición de protagonismo de sus vidas y proyectos biográficos, tienen que orientarse en estructuras de orden hegemónico social. Siguiendo la línea de pensamiento de Judith Butler, en su lectura de Foucault, se constata, sin embargo, que

... el sujeto permanece como tal sólo por medio de la reiteración de sí mismo; una repetición (iterabilidad) en la que el sujeto busca coherencia en categorías sociales que son rearticuladas y resignificadas por él mismo. De acuerdo con su exposición, esta iterabilidad abre posibilidades para oponerse y transformar los términos sociales que lo generan (Romano, 1999: 319).

Con respecto a los procesos de subjetivación y socialización, los cuales se desarrollan en el marco de la migración como practica sociocultural normalizada y en los correspondientes espacios sociales transnacionales, Antonio Vásquez Bianchi (2005) enfatiza, además, el papel de una "ideología de consumismo e individualización", la cual, según el autor, también incide en la normalización de la migración. Al respecto, Roberto comenta:

... la mentalidad que lleva la gente es de hacer dinero y ganar y dinero y dinero y uno...pa' mi mentalidad que yo llevo es tener dinero en mi bolsa y tener cadenas y todo lo que es de un joven me imagino, va (entrevista, mayo de 2009).

Además, aquí se manifiesta un autoposicionamiento de Roberto "como joven", el cual asocia con prácticas de consumo, tales como la compra y la puesta de "cadenas".

\section{Navegando lo incierto: aventura, riesgo y nociones de masculinidad}

Algunos de los jóvenes interpretaban la migración como "una aventura", tal como lo hizo Gabriel, de 17 años, de la Ciudad de Guatemala, quien ya había vivido un tiempo junto a un tío en Arkansas, EE. UU. , al contar lo siguiente en la entrevista:

Gabriel: Iba con motivo de trabajar verdad, pa' poder ayudar en la casa va, pero, aunque no haiga [sic] mucha necesidad pero, yo quería ir por segunda vez a pasear y hacer algo bueno también, va, para ayudar más en la casa y estar un poquito mejor, va. 
Es bonito ir porque esa es la aventura que tal vez, a veces, le digo yo también va, que a veces mucha gente piensa de que cómo será irse va y no entiende cómo es irse y se quedan con la duda va, pero si es bonito, es una buena aventura va, es bonito... y uno dice, ala, si el cruzó como yo no puedo cruzar va, ahi es que le surge a uno la pregunta, va, y ahí es cuando uno empieza en pensar en ir y [sic] intenta y si, como llegan diciendo que, ala, que bueno el camino y que buena aventura, va, y que la gran y entonces por eso es que a uno le sale el deseo de ir, voy a intentar también va (Gabriel, entrevista, abril del 2009. Énfasis agregado, S.D.).

También José, de 17 años y de la región del Petén, usó la palabra "aventura" para referirse a su intento migratorio: "S.D.: ¿Tienes familia en Estados Unidos? José: No, solo voy así a la aventura (risa)" (entrevista con José, abril del 2009). El joven ya había intentado por tercera ocasión llegar a los Estados Unidos y estaba convencido de volver a "irse", pero esta vez deseaba quedarse trabajando un tiempo en Cancún, México, con el fin de ahorrar suficiente dinero para el viaje. En relación con los procesos de socialización vinculados con nociones de género, Mart Busche, recurriendo al sociólogo alemán Michael Meuser, postula que la construcción adolescente de masculinidad muy a menudo es llevada a cabo a través de un comportamiento arriesgado (Risikoverhalten) y su comunicación (Busche, 2014). Es decir, emprender el viaje a EE. UU. en condiciones tan precarias como las que establece el régimen migratorio a través de la ilegalización de dicha movilidad, puede servir también como una manera de performar nociones de masculinidad (Butler, 2007). Asimismo, de la narración de Roberto se desprende que viene de una familia donde las figuras masculinas se convierten en hombres* al generar sus propios ingresos, trabajando "duro" como su papá o sus hermanos con dos trabajos en EE. UU. Comenta Roberto en la entrevista que su cuñado era el que le había contado sobre "la aventura" de cruzar el desierto, de la adrenalina que conlleva cuando la Migra le persigue, como lo contó de manera emocionada Roberto "hasta con helicóptero", como "lo vi en las películas". Entonces, se pudiera llegar a la interpretación que la necesidad de la que tanto habló en la entrevista Roberto, y de la cual dice que no es económica ("yo no tenía necesidad, pero yo quiero ayudarle a mi familia pa' que ellos no digan que solo uno va estar recibiendo y todo y no que no da uno también"), también puede interpretarse como el deseo o la necesidad de poder atribuir una propia historia a este "mito", esta forma ritualizada de contar los acontecimientos del camino al "Norte" (Falla, 2008), le permite inscribirse en este universo (predominantemente percibido como masculino) y autoposicionarse como uno de los (hombres)* que lo ha "vivido para contarlo":

No una historia inventada, pero si una que se parece a un mito por repetición, por la esquematización, por el desprendimiento ligero de la realidad que la repetición conlleva...y por la referencia implícita a una gran colectividad que narra lo mismo, es decir, la experiencia de vida 
o muerte en el paso del país pobre a la opulencia del Norte. Es una historia que recibe respuestas de historias parecidas, cada una más increíble, de miles de otros migrantes (Falla, 2008: 79-80).

\section{Resumen intermediario: experiencias heterogéneas}

Válgase enfatizar a manera de resumen intermediario que el análisis del material empírico sugiere que las experiencias y motivos de los jóvenes son sumamente heterogéneos. Así, algunos de los entrevistados destacaban la inmediata necesidad de irse para proteger su vida después de haber recibido amenazas de muerte por parte de pandillas, o de haber vivenciado la muerte violenta de un familiar a manos de estas, como en el caso de Antonio, un joven del departamento de Santa Rosa y de 17 años, quien clasificaba su experiencia migratoria como "una tontera":

Pues, yo como a mí me han pasado muchas cosas, de primero mataron a mi papá, luego extorsionaron a mi hermano, luego le pegaron a mi hermano, casi lo mataron...se me llenó la cabeza de cosas y ya no quería estar ahí...bueno, después intenté sacar la visa, pero no me la dieron, pero de ahí fue donde más, otro problema encima y por eso tome la decisión de irme (Antonio, entrevista, marzo del 2009).

Como si esto fuera poco, sufrió violencia a manos de "unos pandilleros" en un "refugio" a donde lo había llevado la policía migratoria mexicana y donde fue despojado de todas sus pertenencias. El caso de Antonio demuestra una tendencia que se ha visto aumentada durante los últimos cinco años: la inmediata necesidad de salir de Guatemala como única opción percibida y disponible para salvar la vida ante amenazas de violencia y muerte. Además surgieron en las entrevistas motivos como la necesidad de apoyar a la economía familiar, la reunificación con padres y familiares que desde hace tiempo radican en EE. UU.; y también cobraron relevancia fenómenos como la violencia intrafamiliar y situaciones de desprotección. A la vez, la falta de oportunidades en Guatemala fue mencionada por los jóvenes; por ejemplo en cuanto a encontrar un empleo dignamente remunerado. Mientras algunos querían seguir con sus estudios, todos iban con la idea de trabajar a México o EE. UU.

Estos motivos para migrar solamente pueden ser desagregados con fines analíticos, ya que a menudo están entrelazados y se condicionan mutuamente, como se pudo mostrar en el caso de Roberto. Sin embargo, esto no pareciera ser considerado, por ejemplo, en los discursos de los medios y en las estadísticas oficiales. Después de realizar una lectura preliminar de los motivos por los cuales algunos de los jóvenes entrevistados migraron de manera independiente, se señaló las intersecciones migratorias, las relaciones de poder y los procesos de subjetivación para los cuales, en los casos discutidos de Roberto y Gabriel, cobran relevancia las nociones de masculinidad. Es preciso subrayar, empero, que los motivos para la migración, a pesar de ser 
influenciados por estructuras sociales y estatales, también resultan siendo algo muy subjetivo. Por ende, una perspectiva generalizada y genérica para comprender las razones por las cuales migran actores jóvenes parece limitante. Cabe indicar que tan heterogéneo como los jóvenes entrevistados eran sus posicionamientos en relación con su intento migratorio fallido y el proceso de deportación. Así, varios de los entrevistados interpretaron la detención como una forma de "suerte", ya que, a su ver, de esta manera se salvaron de posibles ataques por parte del crimen organizado en el camino, de los que no habían oído antes de marcharse. Y otros se vieron obligados a adoptar la estrategia de entregarse a la policía con tal de regresar a Guatemala, dado que no contaban con otros recursos para emprender el viaje de retorno.

Dicho lo anterior, este artículo procede a dilucidar el importante papel que desempeña la imaginación y los imaginarios sociales existentes entre jóvenes migrantes acerca de los EE. UU. y su vida "allá", planteándose la pregunta de ¿cómo estas imaginaciones están vinculadas con las prácticas de movilidad?

\section{Otras vidas posibles: imaginando el "Norte"}

En el contexto de la (in)movilidad transnacional (Salazar y Smart, 2011), el término "el Norte" alude a más que una simple categorización geográfica; pues cobra relevancia y sentido tanto social como cultural por encima de las dimensiones topográficas reales que engloba. Tal como he señalado en otro lugar (Dietrich, 2015), y a la manera de Camus (2008), Falla $(2006,2008)$ y Palma (2005), ${ }^{29}$ los imaginarios sociales que existen "del Norte" inciden particularmente en la práctica migratoria. Este "conocimiento conjuntivo" (Mannheim, 1980), que se manifiesta a través de los imaginarios sociales, está profundamente entrelazado con los futuros imaginados, pero no necesariamente alcanzables de manera fáctica, por los jóvenes migrantes entrevistados. Como postula Noel Salazar:

Imaginarios constituidos históricamente-conglomerados representacionales, socialmente compartidos y transmitidos (tanto dentro de una cultura como entre culturas), los cuales interactúan con las imaginaciones personales de las personas y los cuales son usados como estrategias que crean sentidos y contornean el mundo-originan muchos viajes (Salazar, 2011: 576-577. Traducción propia, S.D.). ${ }^{30}$

Aunque el interés académico en la investigación de migración y movilidad ha conceptualizado "el poder" (Salazar, 2011) y "la fuerza" (Appadurai, 2001) de la imaginación como algo distinto a la práctica migratoria, Henrik Vigh destaca que "la migración se convierte en la tecnología de la imaginación, como un acto a través del cual las personas 
llegan a imaginarse vidas mejores, en otros tiempos o lugares" (2009: 94. Traducción propia, S.D.). ${ }^{31} \mathrm{Al}$ mismo tiempo, y siguiendo la línea de pensamiento de Salazar, quien también hace hincapié en la relación de la "lógica cultural de la migración" mencionada previamente en este artículo, cabe destacar que

La migración se relaciona tanto con estos imaginarios como con el movimiento físico fáctico de una localidad a otra y de regreso. Estas imágenes e ideas de otros (entiéndase: mejores) lugares para vivir-muchas veces mal representados por los medios populares-circulan en un espacio global muy desigual y por último están siendo filtrados por las aspiraciones personales de los migrantes. La migración, por ende, siempre requiere de algún conocimiento, o, por lo menos, de rumores acerca del 'otro lado' (Salazar, 2011: 586-587. Traducción propia, S.D.). ${ }^{32}$

Así mismo, Arjun Appadurai hace énfasis en el papel de los medios masivos de comunicación (léase también mediascapes) y señala que

... como nunca antes, muchas más personas en muchas partes del planeta consideran un conjunto mucho más amplio de vidas posibles para sí y para otros...Una fuente muy importante de este cambio son los medios masivos de comunicación, los que presentan a la gente de todo el mundo un rico, y siempre cambiante muestrario de vidas posibles, algunas de las cuales entran con más éxito que otras en las imaginaciones experimentadas por las personas (2001: 68).

Teniendo lo anterior como referente, ¿qué saben los jóvenes entrevistados acerca de estas vidas posibles?, ¿con cuáles rumores "del otro lado" están familiarizados? Partiendo de estas preguntas, se discute lo anterior a través de un análisis más detallado de las narraciones de varios de los jóvenes entrevistados. Valga mencionarse que he encontrado una amplia evidencia del entramado de los imaginarios sociales del "Norte" y la imaginación individual en las entrevistas con quienes participaron en el estudio y que a la vez apuntan a los motivos analizados en las páginas anteriores.

\section{Fantasías televisadas y la vida cotidiana}

Silvio, un joven de 17 años del departamento de Baja Verapaz, compartió cómo se imaginaba la vida en los Estados Unidos de manera muy elaborada. Después de la muerte de su padre, el joven, quien había trabajado como albañil en la Ciudad de Guatemala, solicitó ayuda a sus hermanos que vivían en los Estados Unidos para poder trasladarse a ese país. Al mismo tiempo, y al igual que en el caso de Roberto presentado en las páginas anteriores, se manifiestan varios motivos solapados en el siguiente extracto de la entrevista: 


\section{S.D.: ¿Cómoteimaginaslos Estados Unidosy tuvidaallá?}

Silvio: Pues me imagino bien porque yo miro, miraba muchas programa de televisión estadounidense, o sea, yo miraba todas las personas, yo miro personas ahi, donde salen, como compran, van al supermarket, entran, agarran las cosas, pasan así a pagar [señala, S.D.], con un dólar así y yo miraba, y es más, aprendi un poco de inglés con la televisión y estudiando y entonces yo concuerdo las palabras y al llegar allá, para mí va ser fácil hablar inglés, al quedarme con un gringo que me hable, voy a aprender rápido...entonces al llegar allá trabajar, pintura o restaurante iba yo, ya estaba listo. Es que allá está la junta general de la iglesia y allí iba yo, o sea iba a trabajar, directo iba a trabajar, y a la iglesia y esa era mi vida, o sea pensaba ir a trabajar e ir a la iglesia y hacer mi casa acá en Guatemala, dije yo al irme, ojalá me vaya fácil porque en Estados Unidos ver los edificios, ver las calles, allá todo es diferente, y yo he visto y por tanto ver mi mente se abrió, o sea yo al llegar a Estados Unidos no voy a sentir extraño por lo helado, por lo caliente del verano no...Yo al llegar, yo como que soy de allá, o sea lo que me falta es aprender a vivir allá, porque allá, bueno allá la mayoría come solo cosas así comida chatarra le dicen, pero muchos hacen comida, pero no la mayoría, no la hace, y hay lavanderías y todo, yo sé, entonces dije yo, allá en la mañana, solo café, así es en la tele y todo, en la mañana café y a medio día, a las diez pan con té y medio día lunch y en la noche cena y ya la comida sustenta, entonces dije yo, al llegar allá, no sé si primero dios paso adelante, pero, yo en mi vida ya sabía cómo iba a ser, sabía ya quedarme en un apartamento, a mi casa, la iglesia y el trabajo, sabía que no tenía la libertad de poder salir o bueno ir a un zoológico de alguna ciudad. Yo sí tengo la idea un poco abierta de cómo está allá, el 50 por ciento, ahora lo demás porque no le he vivido, pero sí, al estar allá, yo sé cómo me va ir y todo, me va ir un poco mal y todo porque arriesga uno con la migración siempre... me voy porque quiero experimentar una nueva vida, quiero experimentar esa vida que tanto veo, y que tanto quiero, pero ese era mi sueño y pues me quedé en México (Silvio, entrevista, mayo del 2009. Énfasis agregado, S.D.).

De esta narración se desprende el conocimiento que posee Silvio sobre la vida cotidiana, el cual él mismo atribuye a lo aprendido a través del consumo de series y películas estadounidenses. Así, por medio de su narración, se confirma además lo enunciado por Salazar, para quien el éxito mundial de estos programas de televisión en las últimas décadas "ayudó a convertir a los Estados Unidos en una realidad virtual (Salazar, 2011: 588. Traducción propia, S.D.); ${ }^{33}$ y, de hecho, lo manifiesta Silvio cuando postula: "y yo he visto y por tanto ver mi mente se abrió, o sea yo al llegar a Estados Unidos no voy a sentir extraño por lo helado, por lo caliente del verano no...Yo al llegar, yo como que soy de allá, o sea lo que me falta es aprender a vivir allá" (entrevista con Silvio, mayo del 2009). Al mismo tiempo, comenta que no se sentirá "extraño" en EE. UU., pues está familiarizado debido a su conocimiento del idioma y de las prácticas cotidianas que adquirió a través del consumo de programas de televisión; este "50 por ciento" que ha vivido virtualmente, como bien lo explica más adelante. ${ }^{34}$ 
Esto demuestra, como lo destacan Salazar (2011) y Appadurai (2001), que los medios de (tele)comunicación inciden de manera extraordinaria en la imaginación, pues -a la manera de Appadurai- desplieguen una gama de "vidas posibles". Por lo tanto, "el consumo de estas fantasías televisadas facilita la construcción imaginaria... de la migración como la solución para todos...los problemas" (Salazar, 2011: 589. Traducción propia, S.D.). ${ }^{35}$ Cabe agregar, a la vez, la importancia que han adquirido en los últimos años las redes sociales y páginas interactivas del web 2.0 (por ejemplo: Facebook, Instagram, WhatsApp y Youtube) para mantener la comunicación entre quienes se han ido y quienes se han quedado.

Finalmente, Silvio tematiza la rotura de "su sueño" con la detención en México y la deportación a Guatemala. En consonancia con esto, vale retomar el argumento de Ramona Pérez acerca de la "violencia estructural" inscrita en la detención y la deportación de lxs jóvenes. En el caso de Silvio, el hecho de haber sido detenido y deportado le imposibilitó la realización de su "vida imaginada" en Estados Unidos.

En un nivel más abstracto, sobresalen las implicaciones de estas "fantasías televisadas" acerca de las oportunidades imaginadas como accesibles para el sujeto en los EE. UU. Los jóvenes parecen compartir una clase de conocimiento ("comunicativo" y "conjuntivo") acerca de estas "(no-) posibilidades" (Mecheril y Hoffarth, 2009). Este conocimiento es fomentado a través de las narraciones de las personas que regresan de los EE. UU., de quienes están allá y los medios de telecomunicación.

\section{Imaginarios (pos)coloniales}

Se evidencia además el rol de las relaciones de poder poscolonial. En este contexto, para Vásquez Bianchi "el capitalismo (tanto en la sociedad y no sólo economía) identificado en el estilo de vida de la metrópoli seguirá siendo un incentivo irresistible para la migración a EE. UU." (2005: 105).

Teniendo como referente lo anterior, cabe señalar que el deseo de Silvio de "experimentar una nueva vida", "esa vida que tanto veo y que tanto quiero", se repite a través de todas las entrevistas de este estudio. Las relaciones de poder jerárquicas en un mundo poscolonial que se caracteriza por grandes desigualdades también influyen, entonces, en la decisión de migrar a otro país. En palabras de Noel Salazar:

Los diferentes patrones, las direcciones y motivaciones para la movilidad humana han sido seriamente afectados por el colonialismo. Los imaginarios coloniales acerca de la movilidad horizontal (geográfica) y la vertical-económica (financiera), social (estatus) y cultural (cosmopolita) - aún poseen una influencia enorme. (2011: 578. Traducción propia, S.D.). ${ }^{36}$ 
Vigh (2009) asiente a este argumento y plantea que este "orden global imaginado", "un mundo que se divide en diferente zonas de dominio sobre procesos sociales, políticos, económicos" (94. Traducción propia, S.D.), ${ }^{37}$ influye en la imaginación de jóvenes migrantes. En este sentido, se evidencia una jerarquía de posición geográfica en cuanto al "Norte" y "Sur", centro y periferia.

No obstante, se torna notorio que la anticipación e imaginación del futuro, en el caso de Silvio, la cotidianidad de la vida imaginada en EE. UU., cobran relevancia en cuanto a los procesos de subjetivación cuando jóvenes como Roberto y Silvio apuestan a un "nuevo yo" que procuran encontrar en EE. UU. Este "nuevo yo" estaría transformado no solamente en el sentido de independizarse de la familia de origen, "hacerse hombre" y dejar atrás la categoría de niño* sino también en que este nuevo "yo" sería uno con poder adquisitivo, emancipado de estructuras de pobreza que impedían este consumo vinculado a la realización de un determinado proyecto de vida (Vásquez Bianchi, 2005). A la vez, este "yo" adquiere valor porque desde una perspectiva poscolonial, llegará a transformarse en un "yo" de "metrópoli", desvinculado de la previas experiencias de vida. ${ }^{38} \mathrm{Al}$ respecto, German, un joven del departamento de Guatemala, de 16 años, quien iba con destino a Atlanta, EE. UU., para reunirse con sus padres y hermanos a quienes no había visto en 8 años, manifestó lo siguiente:

\section{S.D.: ¿Y cómo te imaginas la vida en Estados Unidos?}

German: Pues digo yo que es bonito pues, es otra vida, si,... pues o sea... como allí se cambia uno, no sé así, no sé, mira más cosas más bonitas y así, los grandes edificios y todo, los edificios también aqui en Guatemala hay pues, que un mi tío trabaja ahí... pero pues digo yo que es bonito pues, es otra vida, si... allá digo yo que... dice la gente se gana la vida uno ... si eso es lo que pienso... ya no se recuerda de nada... sus amigos y todos eso. Sí. (German, entrevista, abril de 2009. Énfasis agregado, S.D.).

Roberto respondió la misma pregunta del siguiente modo:

\section{S.D.: ¿Y cómo te imaginas la vida en Estados Unidos?}

Roberto: Uh, yo para mí me la imagino virguísima, tenía unas ganas de llegar así como, como es pues, como verla, como es Estados Unidos, pero así que algún otro día lo voy a conocer, va, pero si me lo imagino así con los edificios grandotes y todo, va, así como me imagino los lugares que uno va a visitar y todo, va, me lo imagino bellísimo, sí. (entrevista, mayo de 2009. Énfasis agregado, S.D.). 
Imagen 1

ESTADOS UNIDOS, JOVEN, 16 AÑOS

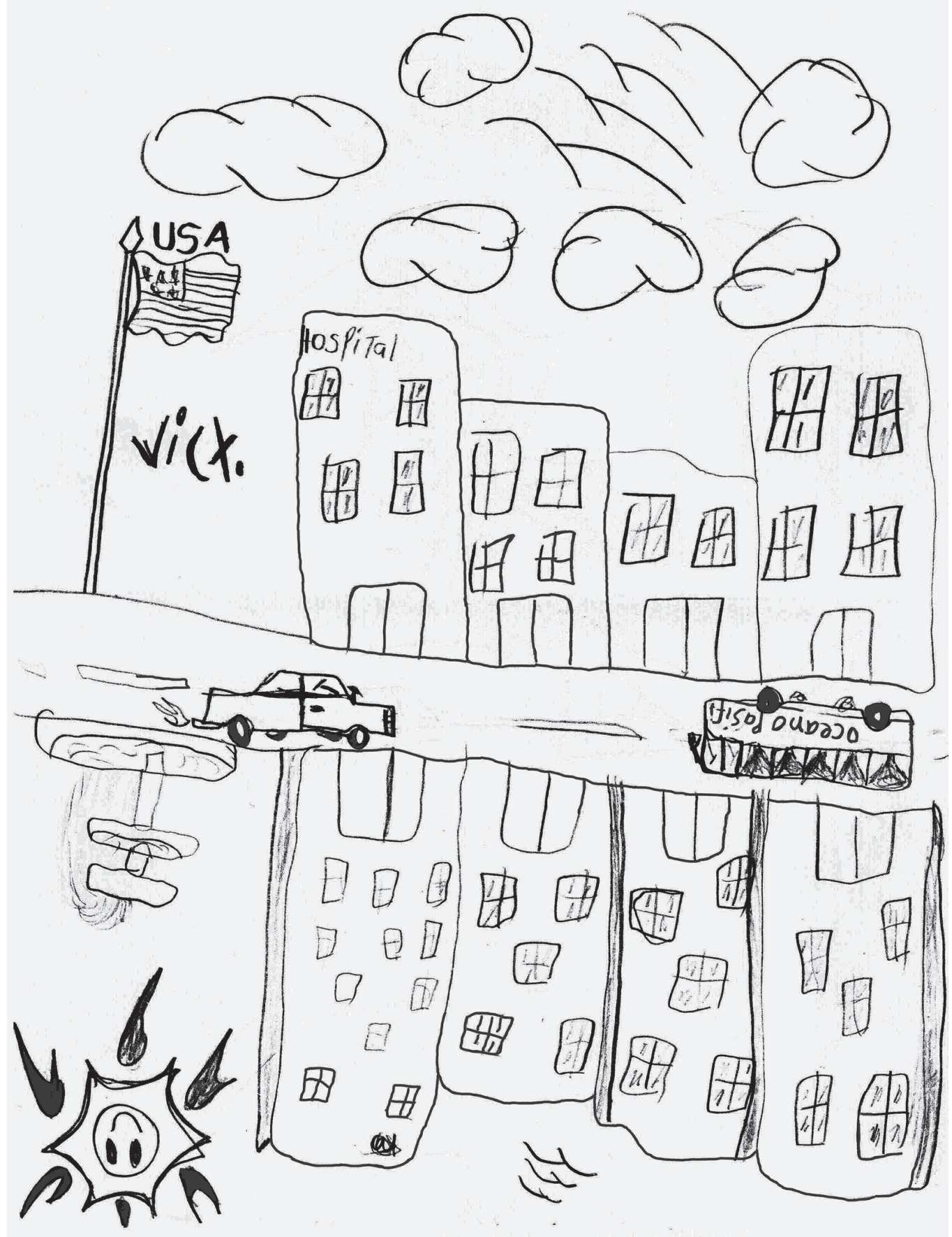


En su narración, tanto Roberto como German resaltan la importancia de conocer los paisajes urbanos y modernos, tal como los retrató un joven de 17 años durante la investigación, apreciable en la ilustración mostrada arriba. La curiosidad de conocer Estados Unidos, “el Norte”, y ver los paisajes ${ }^{39}$ que representan y materializan los imaginarios socioculturales, fue un motivo mencionado con frecuencia en las entrevistas. En este contexto, parece interesante hacer notar que el video musical de la campaña estatal guatemalteca “¿Quédate!”, citado al inicio de este artículo, también enfoca, entre otras imágenes, lugares percibidos y estetizados como destinos turísticos, tales como el lago Atitlán, y paisajes urbanos de la Ciudad de Guatemala. La campaña fue iniciada por la entonces primera dama Rosa Leal de Pérez como reacción frente a la "crisis humanitaria" del año 2014. Al igual que en el dibujo presentado arriba, sale en el video un edificio alto y de una fachada compuesta por ventanas que parecieran epitomizar nociones de modernidad y avance tecnológico, teniendo como "referencia" la arquitectura estadounidense. Llama la atención que el video recurra a estos imágenes con la intención de convencer a lxs jóvenes de no migrar (afuera del país), y que la ciudad capitalina también ofrece la posibilidad de experimentar y vivir "otras vidas" en un entorno de metrópoli poscolonial, sin considerar la violencia simbólica (Bourdieu, 2007) que representa el acceso altamente restringido y desigual a las oportunidades que prometen estos paisajes "modernos".

\section{La otra cara del "Norte": trabajo precario, vicios y maras}

En otro orden, los imaginarios sociales que pueden ser reconstruidos por medio del análisis de las entrevistas a menudo son contradictorios. Así como Silvio, Roberto también está consciente de las condiciones precarias de trabajo y la fragilidad de la vida ilegalizada en EE. UU. Sus hermanos, con 3 años de vivir "allá", le contaron:

Roberto: A para mi, ellos me dicen a mi que es dura, porque dicen que solo es trabajar, mis hermanos trabajan de lunes a viernes y sábado y domingo, porque de lunes a viernes tienen un trabajo y tienen otro de sábado a domingo, si como están ganando muy poco y si está dura la vida en Estados Unidos, no solo es de venir y sentarte y esperar que, que venga el dinero a nosotros, no que, es de trabajar, así, yo por eso me quiero ir le dije, pero tenés ganas de venirte no es solo que la ilusión de irse uno va, y ya allá ya no quieres trabajar y quieres estar solo huevoniando, por eso sí pero, ellos me cuentan que a veces los domingos se van a lugares a visitar, así como a piscinas y todo va, a veces salimos me dice mi hermano, no te voy a decir que no va, o a veces salimos a los centros comerciales a comprar ropa y todo, va, salimos, no está fácil la vida, pero tampoco no es solo trabajar va, me dicen muchas cosas (Roberto, entrevista, mayo de 2009. Énfasis agregado, S.D.).

Al mismo tiempo y aparte de las nociones de "heroísmo" de quienes se arriesgan a emprender el viaje hacia “el Norte” y envían remesas a Guatemala (Girón Solórzano, 2007), 
pareciera formar parte del imaginario colectivo guatemalteco la noción de "irse a perder en los vicios" en los Estados Unidos. En este contexto, durante el trabajo de campo, uno de los jóvenes realizó el siguiente dibujo. En este también se repite el motivo del paisaje urbano, pero esta vez visualizado desde una perspectiva que alude a la asociación de la vida en EE. UU. con el libre consumo de drogas o alcohol en los "bares", como lo señalan las investigaciones de INCEDES (2007), Hondagneu-Sotelo (1994) y Camus (2008). En este contexto, Luis, un joven de 17 años del departamento de Huehuetenango, quien iba a los EE. UU. para reunirse con sus padres y hermanos que ya llevaban años residiendo allá, opinó:

Luis: Yo digo que para los jóvenes, o sea que ahí tienen casas de bares y bueno, uno puedo salir y que tal si, o sea si un joven llega, qué tal si no tiene familiar allá y un joven puede lo que quiere en su vida allá, o sea porque nadie lo está viendo, si, uno se perjudica allá también, si, o sea que alli tienen vicios, tienen vicios digo yo, ...o sea que aqui el vicio de los alcoholes [sic] están caros, pero allá no, o sea son baratos y por eso los compran ellos y ellos se perjudican (Luis, entrevista, marzo de 2009).

Manuela Camus (2008), además, describe cómo en comunidades del departamento de Huehuetenango la "proliferación de 'maras"' es vinculada con la migración al "Norte" al igual que "la pérdida de valores culturales". La cabeza retratada en la imagen, con tres lagrimas abajo del ojo, indica la pertenencia del individuo a una de estas pandillas transnacionales. 


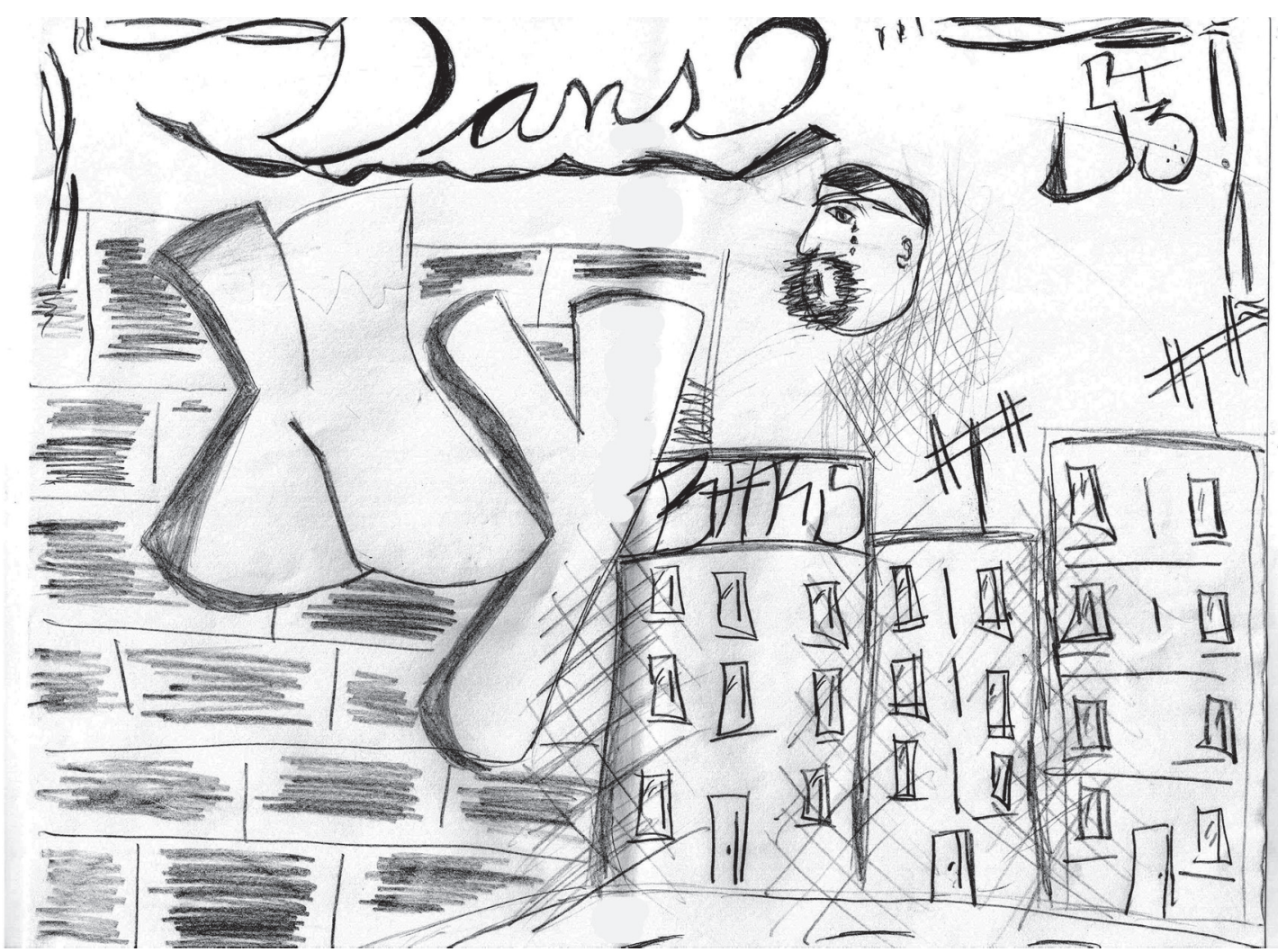

\section{Conclusiones}

Muchas personas están desplazándose en las Américas, tanto nacional como internacionalmente. A estas movilizaciones hacia "el Norte", que transcurren en su mayoría en itinerarios ilegalizados, se suman cada vez más jóvenes centroamericanxs, quienes son motivados por causas disímiles pero a la vez entrelazadas, tal como se argumentó en este aporte. A pesar de las tendencias simplicistas de reducir el entendimiento del fenómeno a una sola causa o contemplarla únicamente como una estrategia racionalmente calculada, este artículo pretendió demostrar la relevancia sociocultural de la migración entendida como primordialmente laboral, uno de los resultados claves de la investigación llevada a cabo en el 2009. Tal como ha sido propuesto en la introducción, se buscó dilucidar la relación entre el "poder de la imaginación" y la decisión de encaminarse "al Norte". En este contexto también se indicó la incidencia de órdenes subjetivizantes en cuanto a la performatividad y escenificación de masculinidad (Butler, 2007) y relaciones de género. 
Sin embargo, es preciso reconocer que las movilizaciones más recientes de jóvenes evidencian los problemas estructurales sumamente arraigados en los acontecimientos histórico-poscoloniales de la región centroamericana. Así, las prácticas migratorias develan cada vez más un carácter forzado, dadas las crecientes desigualdades y violencias estructurales en la región (Sandoval García, 2015). Cabe resaltar, además, la dimensión sociocultural y la conexión de las prácticas migratorias con roles de género heteronormativas, junto al poder de la imaginación y los poderosos imaginarios poscoloniales. Por estas razones, campañas publicitarias estatales como la de "iQuedáte!", que tratan de desalentar la salida de jóvenes del país, no serán exitosas (véase Observatorio de Legislación y Política Migratoria, 15 de enero de 2016). Estas desconocen e ignoran las complejas y hegemónicas dinámicas de las relaciones del poder en los cuales se desarrollan. Desde una perspectiva estatal regulatoria, es preciso, por ende, reconocer a lxs jóvenes actores como agentes sociales dignos y como protagonistas de su vida. Percibiendo a lxs migrantes únicamente como "víctimas" o como "héroes" (Friese, 2016) equivale a negarles una subjetividad más allá de estas concepciones dicotómicas y no alcanza retratar la compleja realidad. A modo de conclusión, pareciera sumamente importante, entonces, cuestionar la práctica de vincular la legitimidad o la ilegitimidad de la movilidad humana a los motivos subyacentes, ya que “¿Cómo distinguimos las diferentes y poderosas fuerzas que obligan la gente a desplazarse? ¿Y cuáles son las consecuencias de imponer una distinción legal entre, por ejemplo, la fuerza de la esperanza y la fuerza de la guerra?" (Elliot, 2016. Traducción propia, S.D.). ${ }^{40}$

\section{Notas}

1 La autora agradece a la persona dictaminadora anónima por los comentarios acerca de una versión anterior de este artículo, al igual que agradece el valioso trabajo de edición por parte de Gabriela Fonseca Argüello.

Cita original: "Look at them leaving in droves, the children of the land, just look at them leaving in droves. Those with nothing are crossing borders. Those with strength are crossing borders. Those with ambitions are crossing borders. Those with hope are crossing borders. Those with loss are crossing borders. Those in pain are crossing borders...They are leaving in droves" (Bulawayo, 2014: 145).

Entiéndase el uso de la "equis" como medida de "desobediencia lingüística", "en los casos en que los genéricos no sean posibles o bien en los casos en que se quiera enfatizar el carácter plural (actual o deseado) en términos de identidad sexual y de género" (Pérez Orozco, 2014: 33).

Véase Sandoval García (2015) en cuanto a las consecuencias de la declaración de la "crisis humanitaria". En este contexto es pertinente reiterar que las organizaciones no gubernamentales guatemaltecas, como la Pastoral de Movilidad Humana (PMH) de la Conferencia Episcopal de Guatemala, entre otras, han estado advirtiendo sobre la relevancia del tema de la movilidad de "menores de edad" en la región y velando por los derechos de estos actores desde hace dos décadas (Méndez Villaseñor, 2014). Sin embargo, como lo resumió el secretario ejecutivo de 
la PMH, Juan Luis Carbajal, “Nadie nos había escuchado hasta que EE. UU. habló” (Méndez Villaseñor, 2014).

Desde una perspectiva crítica que toma en cuenta que el lenguaje perpetúa la reificación y los efectos heteronormativos reduccionistas de las relaciones de género enfocadas en exactamente dos géneros biológicos, el uso de la estrella * indica que los términos engloban también a personas que se autoidentifiquen como niña*/niño* sin que esta identidad coincida necesariamente con su género "biológico".

Cabe destacar que para los fines de este artículo, se concibe al término "jóvenes" como un concepto relacional, heterogéneo y construido sociohistóricamente en contextos específicos (véase Vommaro, 2015).

Cita original: "the simplistic underlying assumption that money is the name of the game for young migrants is unfortunate as it reduces complex social motivations to simple economistic logic" (Vigh, 2009: 92).

El trabajo de campo se llevó a cabo durante 12 semanas, de marzo a mayo del 2009 y fue financiado a través de una beca del Servicio Alemán de Intercambio Académico (DAAD, Deutscher Akademischer Austauschdienst). Obtuve el permiso de llevar acabo 3 meses de investigación cualitativa en un centro estatal de acopio temporal para "menores migrantes" deportados a Guatemala en el año 2009. El centro, ubicado en la ciudad de Quetzaltenango, recibe jóvenes que son "repatriados" desde México en autobús y es administrado por la Secretaría de Bienestar Social de la Presidencia (SBS). Tiene un perfil de atención limitada a 72 horas (véase RELAF y Save the Children y UNICEF, 2015).

9 El término "indígena" tiene su origen en la ideología de dominio colonial, pero ha sido reapropiado por activistas (Oettler, 2008).

Tres jóvenes provenían de la Región Norte (departamentos de Baja Verapaz, Alta Verapaz), uno de la Región Nororiental (departamento de Chiquimula), cinco de la Región Suroriental (departamentos Santa Rosa, Jutiapa), dos de la Región Central (departamento de Escuintla), siete de la Región Suroccidental (departamentos Totonicapán, Suchitepéquez, San Marcos), tres de la Región Noroccidental (departamentos Huehuetenango, Quiché) y tres de la Región de Petén.

Los datos personales de los jóvenes que participaron en el trabajo de campo han sido anonimizados. Los nombres son pseudónimos.

12 Los Zetas son un grupo armado criminal, que en su mayoría recluta a exsoldados guatemaltecos y mexicanos de élite. El grupo se formó a inicios de los años 90 y desde el 2007 opera en la frontera Guatemala-México (Grupo Guatemala-México 2009).

Cabe señalar que todas las entrevistas fueron conducidas en castellano, lo que representa otro limitante del estudio; pues para una parte significativa de jóvenes que son deportadxs desde México y Estados Unidos, el castellano no es el primer idioma. Hubiera sido una ventaja contar con los servicios de traductores de idiomas "mayas". La falta de la presencia de traductores representa tan solo un aspecto de las justificadas críticas en cuanto al proceso de "repatriación" enunciadas por instituciones que velan por el respeto de los derechos de los "menores" migrantes y que también son confirmadas por los resultados de la investigación que llevé a cabo (véase Musalo y Ceriani Cernadas, 2015; Girón Solórzano, 2014; RELAF y Save the Children y UNICEF, 2015, Dietrich, 2015). 
Cita original: "such an ethnography's mimicking and continuing [of, S.D.] the surveillance of already interrogated individuals" (Peutz, 2006: 219).

En cuanto a una evaluación crítica de la producción académica de conocimiento y correspondientes preguntas de "objetividad", válgase remitir a lo que conceptualiza Donna Haraway como "conocimiento situado", para marcar una posición de conocimiento parcial, siempre ligado a la subjetividad y a los contextos específicos de quien realiza la investigación (1988).

Cita original: "to more adequately capture the complex interplay of agency, power and structure within migration contexts" (Clark.Kazak, 2012: 95).

Cita original: ... child migrants often play an active role in assessing their own situation, making decisions about their life trajectories, and negotiating the challenges and opportunities posed by displacement. Although they experience migration as the outcome of their personal circumstances, the option to migrate itself is socially produced (Ensor y Goździak, 2010: 3).

Cita original: "Those social spaces not only consist of financial remittances and shared imaginaries but also of people and families moving back and forth (voluntarily and involuntarily), in a dynamic yet deeply interwoven way." (Dietrich, 2015: 2).

Cita original: "exclusivly male networks [that] favor the migration of men" (Hondagneu-Sotelo, 1994: 188).

Obsérvese que Tanya Golash-Boza y Pierrette Hondagneu-Sotelo indican que nociones de género también inciden en la práctica de detención y deportación en los EE. UU.: "Casi todas estas personas recientemente deportadas han sido hombres latinos, creando así una crisis en familias y comunidades latinas. Sugerimos que esto constituye un programa de deportación racial y en relación al género y argumentamos que los cambios en la legislación inmigratoria, la guerra contra el terrorismo, la aplicación de la ley en cuanto a prácticas de detenciones relacionadas al perfil racial y la criminalización de hombres latinos, y la crisis de desempleo masculino en los Estados Unidos, han producido esta crisis de deportación". [Nearly all of these recent deportees have been Latino men, creating a crisis in Latino families and communities. We suggest this constitutes a gendered racial removal program, and argue that changes in immigration law, the War on Terror, the law enforcement racial profiling and criminalization of Latino men, and the male joblessness crisis in the United States have produced this deportation crisis] (2013: 272. Traducción propia, S.D.).

En este sentido también se acentúa, que al contemplar género como categoría estructural y estructurante, es preciso resaltar sus intersecciones con otras relaciones de poder hegemónicas tales como la pertenencia a una clase y un entorno social (milieu), procesos de racialización/ etnización, la orientación sexual y en el caso migratorio, el estatus legal.

Cita original: "It is well known that throughout many areas of Mexico, young men are seeped in a culture of northbound migration. Sustained by vibrant transnational social networks and by the glories of return migrants, popular folklore defines a journey northward as a rite of passage" (Hondagneu-Sotelo, 1994: 191).

Se manifiesta la inmediata necesidad de conducir más investigación con y sobre jóvenes mujeres* con tal de no seguir perpetuando un "sesgo de género" (Dietrich, 2015: 5. Traducción propia, S.D.). Válgase indicar que hay un video disponible en Youtube titulado "Pa' Capital" (de Fernando Scheel y Raquel Pajoc), en el cual la protagonista cuenta que se "vino sola" a 
la capital guatemalteca para estudiar, conocer "una nueva vida" y "luchar por mis sueños". Aunque la historia que cuenta Raquel Pajoc coincida solo parcialmente con sus experiencias, dado que la joven, quien canta en kaqchiquel y castellano, en una entrevista dice haberse venido a la capital junto a sus padres, el tema del video remarca que también las jóvenes son protagonistas migratorias y protagonistas de sus proyectos de vida. Amerita resaltar, entonces, que hay una sólida base de publicaciones que tematizan la experiencia de mujeres* como actores independientes de migración con diferentes enfoques y que dan constancia de una "feminización de la migración" (véase Castels y Miller, 1993; Han, 2003; Ehrenreich y Hochschild, 2002).

24 Cita original: "Thus male migrant labor is produced by patriarchy for the benefit of U.S. capital" (Hondagneu-Sotelo, 1994: 188).

25 Cita original: "On both sides of the border young male Mexican bodies have ceased to evoke an image of strength, stability, and success when they are unable to perform their masculinity; instead, in both countries, albeit for different reasons, they have come to represent failure. The reality that many will find themselves back on the street, with or without family, is real and reinforces a system of gendered discrimination that publicly marks them as failures and assures their defeat in attaining the desire to be successful providers for their families. Neither country offers the youth an opportunity to see themselves as a successful adult male that will not be marked by their failed attempt to migrate" (Pérez, 2012: 79).

26 Cabe destacar que la necesidad de pagar las deudas acumuladas para solventar el viaje representan una de las razones por las cuales algunxs jóvenes se ven obligadxs a marcharse nuevamente.

Surge como interrogante, entonces, ¿qué deja ver del proceso de "repatriación digna y segura" si lxs jóvenes aprenden la lección, que la solución para llegar al "Norte" consiste en negar ser "menor no acompañado" o "menor de edad"?

Cita original: “[Die Adoleszenz ist als sozial konstruierter Handlungsraum zu verstehen], in dem kulturelle Werte und Praktiken von einer Generation an die nächste weitergegeben werden und in dem Neues entstehen kann" (Busche, 2014: 222).

Vale la pena dirigir la atención a la publicación coordinada por Silvia Irene Palma C. (2005) que lleva el título "Después de Nuestro Señor, Estados Unidos", el cual la autora explica de la siguiente manera: "Es una invitación a la reflexión sobre el futuro de una importante porción de la población que no logra imaginar su proyecto de vida en el lugar donde nació y debe apoyarse en sus creencias religiosas casi como única alternativa para manejar el presente, al mismo tiempo que asume, por su propia cuenta y riesgo, lo que su país no le proporciona objetivamente" (2004b: 19). Así, el título hace alusión a la importancia y la influencia que cobran los imaginarios sociales de los EE.UU., es decir, del "Norte".

Cita original: "Historically laden imaginaries—socially shared and transmitted (both within and between cultures) representational assemblages that interact with people's personal imaginings and are used as meaning-making and world-shaping devices-are at the roots of many travels..." (Salazar, 2011: 576-577).

31 Cita original: "migration becomes a technology of the imagination, as an act through which people come to imagine better lives in other times or places" (Vigh, 2009: 94).

32 Cita original: "[m]igration is as much about these imaginaries as it is about the actual physical movement from one locality to another and back. The images and ideas of other (read: better) 
possible places to live-often misrepresented through popular media-circulate in a very unequal global space and are ultimately filtered through migrants' personal aspirations. Migration thus always presupposes some knowledge or, at least, rumors of 'the other side'" (Salazar, 2011: 586-587).

Es pertinente resaltar, sin embargo, que esta cotidianidad presentada a través de series y películas de la industria cinematográfica, exitosas a nivel mundial, es una cotidianidad ficcionalizada, la cual no alcanza retratar la heterogeneidad de la "realidad" de las condiciones de vida en EE. UU.

Cita original: "[t]he consumption of these televised fantasies facilitates the imaginative construction of ...migration as a solution to all...problems" (Salazar, 2011: 589).

Cita original: "The different patterns, directions, and motivations of human mobilities were severely affected by colonialism. Colonial imaginaries about horizontal (geographical) as well as vertical-economic (financial), social (status), and cultural (cosmopolitan)—mobility still have a huge influence (2011: 578).

Cita original: "a world that is divided into different zones of mastery over social, political, economic processes" (Vigh, 2009: 94).

Este "yo" posiblemente esté condenado a seguir experimentando violencia estructural por su condición de residencia ilegalizada, "mano de obra barata" y "masculinidad dominada y marginalizada". Bulawayo escribe en su obra novelística: "Oíamos todo esto pero lo dejamos entrar por un oído y salir por el otro, pretendiendo no haberlo escuchado. No se nos podía hacer cambiar de parecer, no les hacíamos caso; íbamos a ir a América [los Estados Unidos, S.D.]...Y cuando llegamos a América, tomamos nuestros sueños y los contemplamos con ternura, como si fueran bebes recién nacidos, y los guardamos; no los íbamos a alcanzar. Nunca íbamos a llegar a ser lo que habíamos anhelado ser." [We heard all this but we let it enter in one ear and leave through the other, pretended we did not hear. We would not be moved, we would not listen; we were going to America... And when we got to America we took our dreams, looked at them tenderly as if they were newly born children, and put them away; we would not be pursuing them. We would never be the things we wanted to be] (Bulawayo, 2014: 241. Traducción propia, S.D.).

A la vez es interesante como estas imágenes e imaginarios sociales son globalizados y fomentados por los mismos Estados, por ejemplo a través de sus políticas de representación en el marco de la industria turística. En este sentido, cabe destacar el despliegue y la puesta en escena en las redes sociales por ejemplo de la Embajada Alemana en Guatemala a través de su cuenta en Facebook. Lo que aquí se manifiesta es un lógica hegemónica que distingue entre "turistas", es decir, a quienes hay que incentivar a viajar a Alemania para que generen ingresos a la economía local y luego se regresen, y las personas categorizadas como "otros" ("migrantes", "refugiados") que consumen las mismas imágenes de paisajes idílicos y de calidad de vida, pero que se enfrentan a enormes desafíos burocráticos impuestos por un régimen migratorio arbitrario.

$40 \quad$ Cita original: "How do we distinguish the different, powerful forces that compel people to move? And what are the consequences of imposing a legal distinction between, say, the force of hope and the force of war?" (Elliot, 2016). 


\section{Bibliografía}

Appadurai, Arjun. La Modernidad Desbordada. Buenos Aires: Ed. Trilce S.A., 2001.

Bourdieu, Pierre. "The forms of capital". Handbook of Theory and Research for the Sociology of Education. Ed. John G. Richardson. New York: Greenwood, 1986. 241-258. El sentido práctico. Buenos Aires: Siglo XXI Editores, 2007.

Boyden, Jo y Judith Ennew. Children in focus - A manual for participatory research with children. Stockholm: Rädda Barnen. 1997.

Broughten, Chad."Migration as engendered practice:Mexican men, masculinity, and Northward migration". Gender y Society, 22 (2008): 568-589. Doi:10.1177/089124320832127

Bulawayo, NoViolet. We need new names. London: Vintage Books, 2014.

Busche, Mart. "Männlichkeit und Gewaltabstinenz: Dynamiken im adoleszenten (Ver) Handlungsraum" [Masculinidad y abstinencia de la violencia: dinámicas en el espacio adolescente de acción y negociación]. Verorten - Verhandeln - Verkörpern. Interdisziplinäre Analysen zu Raum und Geschlecht [Localizar - negociar - encarnar. Análisis interdisciplinario del espacio y de género]. Silke Förschler, Rebekka Habermas y Nikola Roßbach (Eds). Bielefeld: transcript. 2014. 219-248.

Butler, Judith. El género en disputa. El feminismo y la subversión de la identidad. Barecelona: Paidós Ibérica, 2007.

Camus, Manuela. La sorpresita del Norte. Migración internacional y comunidad en Huehuetenango. Guatemala: INCEDES/CEDFOG, 2008.

Castels, Stephen y Mark J. Miller (Eds.). The Age of Migration: International Population Movements in the Modern World. New York: The Guilford Press, 1993.

Centro de Derechos Humanos Fray Matías de Córdoba A.C. Comunicado de Prensa, 2016. <http:// cdhfraymatias.org/sitio/wpcontent/uploads/2016/01/COMUNICADO_0116.pdf >.

Chavez, Leo R. "The condition of illegality". International Migration 45 (2007): 192-196. Doi:10.1111/j.1468-2435.2007.00416.x

Clark-Kazak, Christina. "Conclusions, Reflections, and Prospects for Future Research, Policy, and Programming". Independent child migration - Insights into agency, vulnerability, and structure. New directions for child and adolescent development. Orgocka, Aida y Christina Clark-Kazak (Eds.). San Francisco: Jossey-Bass. 2012, N. ${ }^{\circ} 136.93-98$.

Coutin, Susan Bibler. “Being en route". American Anthropologist, 107 (2005): 195-206.

De Genova, Nicolas P. "Migrant 'Illegality' and deportability in everyday life". Annual Review of Anthropology, 31 (2002): 419-447. Doi:10.1146/annurev.anthro.31.040402.085432

Dietrich, Sarah. Migration und Deportation aus der Sicht unbegleiteter guatemaltekischer Jugendlicher - Minderjährige Migranten im Spannungsfeld zwischen Agency und Vulnerabilität [Migración y deportación desde la perspectiva de jóvenes guatemaltecos no acompañados - Menores migrantes entre agency y vulnerabilidad]. Tesis de maestría no publicada. Instituto de Antropología Social y Cultural. Alemania: Universidad de Friburgo, 2010.

"'Why are we put in prison?' - Independent Guatemalan minor migrants' experiences of transnational childhoods". Transnational Social Review: A Social Work Journal. 5: 2 (2015): 1-15. Doi: 10.1080/21931674.2015.1035883

Ehrenreich, Barbara y Arlie Russell Hochschild. Global Woman. Nannies, Maids and Sex Workers in the New Economy. London: Granta Books, 2002.

Elliot, Alice. "Forceful Hope". Allegra Lab: Anthropology, Law, Art, World, $2016<$ http://allegralaboratory.net/forceful-hope/>. 
Ensor, Marisa O. y Elżbieta M. Goździak (Eds.). Children and migration: At the crossroads of resiliency and vulnerability. New York: Palgrave, 2010.

Escobar Sarti, Carolina. Los pequeños pasos en un camino minado: Migración, niñez y juventud en Centroamérica y el sur de México. 2008. <http://www.elsoca.org/pdf/Libro.caminominado.pdf $>$.

Falla, Ricardo. Juventud de una comunidad maya, Ixcán, Guatemala. Guatemala: AVANCSO/ USAC, 2006.

. Migración transnacional retornada. Juventud indígena de Zacualpa, Guatemala. Guatemala: AVANCSO/USAC, 2008.

Friese, Heidrun. Flüchtlinge: Opfer - Bedrohung - Helden. Zur politischen Imagination des Fremden [Refugiados: victimas-peligro-héroes. La imaginación política de lo desconocido]. Bielefeld: transcript, 2016.

Global Detention Project. Mexico detention profile. Updated 2013. <http://www.globaldetentionproject.org/countries/americas/mexico/introd uction.html $>$.

Girón Solórzano, Carol. Monografía aldea Llano Grande, Pachalúm, el Quiché. Guatemala: INCEDES. 2007.

- Actualización: Diagnóstico nacional sobre la situación de niños, niñas y adolescentes migrantes no acompañados, en el proceso migratorio. Comisión Pastoral de Movilidad Humana, Conferencia Episcopal Guatemala. 2014. <http://www.movilidadhumana. com/wpcontent/uploads/2014/08/revistaactualizacion -pmh.pdf $>$.

Golash-Boza, Tanya y Pierrette Hondagneu-Sotelo. “Latino Immigrant Men and the Deportation Crisis: A Gendered Racial Removal Program”. Latino Studies 11, 3 (2013): 271-292.

Grupo Guatemala-México. Migración y Desarrollo 2009: Las Politicas Migratorias de México y Guatemala, 2009. <http://mexicoguatemala.colmex.mx/e107_files/downloads/Las_ politicas_migrat Orias_mexicoguatemala.pdf $>$.

Han, Petrus. Frauen und Migration [Mujeres y Migración]. Stuttgart: Lucius \& Lucius, 2003.

Haraway, Donna. "Situated Knowledges: The Science Question in Feminism and the Privilege of Partial Perspective". Feminist Studies, 14, 3 (1988): 575-599.

Hondagneu-Sotelo, Pierrette. Gendered Transitions. Mexican Experiences of Immigration. Berkley and Los Angeles, California: University of California Press, 1994.

Hondagneu-Sotelo, Pierrette y Michael Messner. "Gender Displays and Men's Power: The 'New Man' and the Mexican Immigrant Man”. Harry Brod y Michael Kaufman (Eds.). Theorizing Masculinities. Newbury Park, California: Sage Publications, 1994. 201-218.

INCEDES (Instituto Centroamericano de Estudios Sociales y Desarrollo). Observatorio para la gestión social de la migración a Estados Unidos. Guatemala: INCEDES, 2007.

Kron, Stefanie. "Prácticas de ciudadanía y migración transnacional. Notas sobre la zona fronteriza guatemalteca-mexicana". Gioconda Herrera y Jacques Ramírez (Eds.). América Latina migrante: estado, familias, identidades. Quito: FLACSO - Sede Ecuador: Ministerio de Cultura del Ecuador, 2008. <http://www.flacsoandes.edu.ec/libros/digital/40827.pdf>.

Mannheim, Karl. "Eine soziologische Theorie der Kultur und ihre Erkennbarkeit (Konjuktives und Kommunikatives Denken)" [Una teoría sociológica de la cultura y su conocimiento (pensamiento conjuntivo y comunicativo]. Strukturen des Denkens [Estructuras del pensamiento]. David Kettler, Volker Meja y Nico Stehr (Eds.). Frankfurt am Main: Suhrkamp. 1980. 155-312.

Mecheril, Paul y Britta Hoffarth. "Adoleszenz und Migration. Zur Bedeutung von Zugehörigkeitsordnungen [Adolescencia y Migración. En cuanto al significado de 
ordenes de pertenencia]". Vera King y C. Koller (Eds.). Adoleszenz - Migration - Bildung [Adolescencia- Migración- Educación]. Wiesbaden: VS-Verlag, 2009, 239-258.

Méndez Villaseñor, Claudia. "Nadie nos había escuchado hasta que EE. UU. habló". El Periódico. Ciudad de Guatemala: 22 agosto 2014. <http://elperiodico.com.gt>

Musalo, Karen y Pablo Ceriani Cernadas. (Eds./Coord.) Niñez y migración en Centro y Norte América: causas, políticas, prácticas y desafíos. San Francisco y Buenos Aires: Center for Gender y Refugee Studies, University of California Hastings College of the Law ; Centro de Justicia y Derechos Humanos. Universidad Nacional de Lanús, 2015. <http://www.acnur.org/t3/fileadmin/Documentos/Publicaciones/2015/9927.pdf>.

Observatorio de Legislación y Política Migratoria. "Fracasa campaña para reducir migración de menores a EE. UU.". 16 enero 2016. <http://observatoriocolef.org/Noticia/3004>.

O' Connell Davidson, Julia y Caitlin Farrow. Child Migration and the Construction of Vulnerability. Save the Children Sweden, 2007.

Oettler Anika. Die lateinamerikanische Bevölkerung [La población latinoamericana]. Informationen zur politischen Bildung. Lateinamerika 300 (2008): 17-20.

Orgocka, Aida y Christina Clark-Kazak (Eds.). Independent child migration - Insights into agency, vulnerability, and structure. New directions for child and adolescent development, N. 136. San Francisco: Jossey-Bass, 2012.

Palma C., Silvia Irene. "Presentación". Silvia Irene Palma C. (Coord.). Después de Nuestro Señor, Estados Unidos. Perspectivas de análisis del comportamiento e implicaciones de la migración internacional en Guatemala. Guatemala: FLACSO, Fundación Soros, Ford Foundation, 2005: 13-19.

Pelican, Michaela. "International Migration: Virtue or Vice? Perspectives from Cameroon". Journal of Ethnic and Migration Studies 39, 2 (2012): 237-258. Doi:10.1080/136918 3X.2013.723256

Pérez, Ramona. "Crossing the border from boyhood to manhood: male youth experiences of crossing, loss, and structural violence as unaccompanied minors". International Journal of Adolescence and Youth 19, 1 (2012): 67-83. Doi: 10.1080/02673843.2012.708350

Pérez Orozco, Amaia. Subversión feminista de la economía. Aportes para un debate sobre el conflicto capital-vida. Madrid: Traficantes de Sueños, 2014. <http://www.traficantes.net/sites/ default/files/pdfs/map40_subversion_feminista.pdf $>$.

Peutz, Nathalie. “Embarking on an Anthropology of Removal”. Current Anthropology 47 (2006): 217-241.

Pries, Ludger. “Transnationale soziale Räume. Theoretisch-empirische Skizze am Beispiel der Arbeitswanderung Mexiko-USA" [Transnational social spaces. Theoretic-empirical outline drawing from the example of labor migration Mexico-USA]. Ulrich Beck (Ed.). Perspektiven der Weltgesellschaft [World society's perspectives]. Frankfurt: Suhrkamp, 1998: 55-86.

PDH (Procurador de los Derechos Humanos). Derribando Muros. La Realidad de la Niñez y Adolescencia Migrante en la frontera Guatemala-México. Guatemala Ciudad: Defensoría de la Población Desarraigada y Migrante/Defensoría de la Niñez y la Juventud, 2005.

RELAF y Save the Children y UNICEF. Niñas, niños, adolescentes migrantes retornados. Un análisis de los contextos y las respuestas de los servicios y las políticas de protección en El Salvador, 
Guatemala, Honduras, y México. Buenos Aires, 2015. <http://www.relaf.org/materiales/ INFORME\%20MIGRANTES\%20RELAF\%20ST C\%20UNICEF.pdf>.

Romano, Patricia. "Judith Butler y la formación melancólica del sujeto". Economía, Sociedad y Territorio 2, 6 (1999): 313-327. <http://www.redalyc.org/pdf/111/11100608.pdf >.

Salazar, Noel. "The Power of Imagination in Transnational Mobilities". Identities: Global Studies in Culture and Power, 18 (2011): 576-598. Doi: 10.1080/1070289X.2011.672859

Salazar,Noely AlanSmart. “Anthropological takeson(Im)mobility:Introduction”. Identities: Global Studies in Culture and Power, 18, (2011) i-ix. Doi: 10.1080/1070289X.2012.683674

Sandoval García, Carlos. "To whom and to what is research on migration a contribution". Ethnic and Racial Studies 36, 9 (2013): 1429-1445. Doi: 10.1080/01419870.2013.800218

Sandoval García, Carlos. No más muros: exclusión y migración forzada en Centroamérica. San José (Costa Rica): Editorial UCR, 2015. <http://www.cpalsocial.org/documentos/190.pdf >. Sandoval Palacios, Juan Manuel. "USA: Der militärisch-industrielle Komplex der Migration" [USA: The immigration military-industrial complex]. Lisa-Marie Heimeshoff, Sabine Hess, Stefanie Kron, Helen Schwenken, y Miriam Trzeciak (Eds.) Grenzregime II. Migration, Kontrolle, Wissen. Transnationale Perspektiven [Border regimes II. Migration, control, knowledge. Transnational perspectives]. Berlin y Hamburg: Assoziation A, 2014. 75-83.

Scheper-Hughes, Nancy. "A Talent for Life: Reflections on Human Vulnerability and Resilience". Ethnos 73, 1 (2008): 25-56.

Tuckmann, Jo. "'Flee or die': violence drives Central America's child migrants to US border". The Guardian. 9 Jul. 2014. [fecha de último acceso: 08.06.16] <http://www.theguardian. com/world/2014/jul/09/central-america-child-migrants-us-border-crisis >.

Uehling, Greta. "The international smuggling of children: Coyotes, snakeheads, and the politics of compassion". Anthropological Quarterly 81 (2008): 833-871.

Vásquez Bianchi, Antonio. "Factores condicionantes de la migración a Estados Unidos en Comunidades rurales". Silvia Irene Palma C. (Coord.). Después de Nuestro Señor, Estados Unidos. Perspectivas de análisis del comportamiento e implicaciones de la migración internacional en Guatemala. Guatemala: FLACSO, 2005. 91-107.

Vigh, Henrik. "Wayward migration: On imagined futures and technological voids". Ethnos 74 (2009): 91-109. Doi: 10.1080/00141840902751220

Vommaro, Pablo. “Guía de clase: Producción social del espacio, territorialidad y prácticas políticas juveniles". Movilización social, activismo y acción colectiva juvenil en América Latina y el Caribe. Seminario Virtual CLACSO. Documento no publicado, 2015.

West, Candance y Don Zimmerman. “Doing gender". Gender y Society 1 (1987): 125-151.

Sarah Dietrich. Alemana, cuenta con el título de Magistra Artium en Antropología Social y Cultural, Estudios de Género y Ciencias Políticas otorgado por la Universidad Albert-Ludwig de Friburgo, Alemania. Actualmente es docente y asistente de investigación en el área de Pedagogía Intercultural de la Universidad Técnica de Chemnitz, Alemania. Es miembro cofundadora del grupo investigativo universitario "Personas refugiadas en Sajonia", constituido en el 2015. Ha realizado prácticas 
profesionales y estudiantiles con la Agencia Alemana de Cooperación Internacional (GIZ), Eschborn, Alemania; con el Instituto Centroamericano de Estudios Sociales y Desarrollo (INCEDES), Ciudad de Guatemala y la Fundación Myrna Mack, Ciudad de Guatemala. Su artículo "Why are we put in prison?" - Independent Guatemalan minor migrants' experiences of transnational childhoods se publicó en mayo del 2015 en la revista Transnational Social Review: A Social Work Journal, Vol. 5: 2. Instituto de Ciencias de la Educación, Universidad Técnica de Chemnitz, Reichenhainerstr. 41, 09126, Chemnitz, Germany.

Contacto: sarah.dietrich@phil.tu-chemnitz.de 